\title{
Developing Equivalent Surface Heat Transfer Input Parameters for Updated Standard 140/BESTEST Thermal Fabric Test Cases
}

\author{
J. Neymark ${ }^{1}$, M. Kummert ${ }^{2}$, R. Judkoff ${ }^{3}$ \\ ${ }^{1}$ J. Neymark \& Associates, Golden, Colorado, USA \\ ${ }^{2}$ Polytechnique Montréal, Montréal, Quebec, Canada \\ ${ }^{3}$ National Renewable Energy Laboratory, Golden, Colorado, USA
}

\begin{abstract}
ANSI/ASHRAE Standard 140, Standard Method of Test for the Evaluation of Building Energy Analysis Computer Programs, is widely cited for evaluating software for use with performance-path energy efficiency analysis in conjunction with well-known energy-efficiency standards, including: ASHRAE Standard 90.1, the International Energy Conservation Code, and other international standards. This paper summarizes recent work to develop improved equivalent surface heat transfer input parameters for the building thermal fabric comparative test cases that comprise a portion of Standard 140. The software-to-software comparative test method allows comparison of simulation results from a wide variety of building energy simulation programs to each other. In this type of test method, it is of great importance to specify inputs that are as well-equivalenced as possible to accommodate a wide variety of input schemes for the tested programs, and thereby reduce the potential for disagreements among them in the tests. Results include new alternative constant surface coefficients that are appropriate to the test cases and demonstrate their ability to approximate the more detailed surface heat transfer models from which they are derived.
\end{abstract}

\section{Introduction}

Background: ANSI/ASHRAE Standard 140 and The Building Energy Simulation Test and Diagnostic Method (BESTEST)

ANSI/ASHRAE Standard 140, Standard Method of Test for the Evaluation of Building Energy Analysis Computer Programs (ANSI/ASHRAE 2017), is widely cited and applied for evaluating software for use with performancepath energy efficiency analysis in conjunction with wellknown energy-efficiency standards, including ASHRAE Standards 90.1 and 189.1, the International Energy Conservation and International Green Construction Codes, and other international standards. (ANSI/ ASHRAE/IES, 2016; ANSI/ASHRAE/IES/USGBC 2017; Crawley et al 2005; IECC 2018) A more complete listing is included in Neymark et al (2017).

The development of practical procedures and data for tool evaluation and improvement is part of an overall validation methodology that National Renewable Energy Laboratory (NREL), the International Energy Agency (IEA), and the American Society of Heating, Refrigerating, and AirConditioning Engineers (ASHRAE) have developed for many years. (ASHRAE, 2017, Chapter 19; ANSI/
ASHRAE, 2017; Bloomfield, 1989; Judkoff, 1988; Judkoff and Neymark, 2006).

Diagnosing sources of disagreement is fundamental to the BESTEST method. This is accomplished by eliminating or mitigating known sources of disagreement so that we can identify unknown sources of disagreement for the continuous improvement of building energy models (BEMs).

\section{Input Equivalency}

A key aspect of the BESTEST method is to specify test cases such that equivalent input files can be defined for a variety of detailed and simplified building energy simulation tools. Input equivalence is not always a straightforward concept, especially where the modeling approach varies significantly between programs. Even if all specification ambiguities and model input errors are eliminated, legitimate differences in interpretation can lead to significant differences in simulation results. To minimize interpretive issues, input information is provided at several levels of physical detail. (Judkoff and Neymark, 2013)

\section{Aim and Approach}

The IEA BESTEST (Building Energy Simulation Test) thermal fabric tests, originally published in 1995 (Judkoff and Neymark, 1995), comprise a portion of ASHRAE Standard 140. These are a set of program-to-program comparative tests, where to assess model accuracy a tested program's results are compared with the range of agreement based on the results of other programs that are typically a set of vetted example results provided with Standard 140.

However, for some test case results, the Standard 140 example results range of agreement among a variety of programs compared to each other is large. For example, in Figure 1 (see "Results") the range of disagreement for annual heating load results published in 1995 is $28 \%$ and $54 \%$ for the BESTEST low mass and high mass base cases, respectively. Differences among programs that contribute to these disagreements are described in modeler reports included with IEA BESTEST. Reducing this results disagreement is important because it provides a basis for improving user confidence in BEMs.

The aim of this work is to narrow the range of agreement among BESTEST/Standard 140 building thermal fabric test suite example simulation results by better defining the original test specification related to surface heat transfer modeling. This also enhances the diagnostic power of the test suite to find other sources of disagreement. 
The approach of the work is to: 1) update current BESTEST input specifications relevant to recent improvements in the state of the art in surface heat transfer modelling, 2) update alternative approximate annually constant buoyancy-driven convective-only and combined convective-and-radiative heat transfer coefficients consistent with known modeling improvements and compare them with the 1995 coefficients, and 3) assess the effect of surface heat transfer specification improvements on simulated loads.

This work to improve equivalent surface heat transfer input parameters is an important component of the overall project to update the building thermal fabric tests of Sections 5.2.1, 5.2.2, and 5.2.3 of Standard 140, in collaboration with ASHRAE SSPC 140 (the Standard 140 project committee) and other international BEM software developers (Judkoff and Neymark, 2013).

\section{Alternative constant surface heat transfer coefficients in original BESTEST}

Convective and radiative heat transfer from building surfaces substantially affects the calculation of steadystate conduction through windows and uninsulated opaque surfaces, insulated opaque surfaces exposed to direct sunlight, thermal storage dynamics for all surfaces, thermostat operation, etc. The original thermal fabric BESTEST specifications allow/encourage automated calculation of surface convection and radiation heat transfer. BESTEST also provides approximate default constant combined (convective and radiative) interior and exterior surface coefficients and the radiative portion of these coefficients to accommodate software that does not contain more sophisticated dynamic modeling of convective and radiative surface heat transfer.

For interior surface coefficients, original test case default values for combined coefficients are based on ASHRAE Handbook of Fundamentals (1981), p. 23.12, Table 1 (also see ASHRAE 2017, p. 26.21, Table 10; the original "pre-ASHRAE" source is not obviously cited). For exterior surface coefficients, original test case default combined surface coefficients values are based on applying a second-order polynomial in wind speed, where wind speed is taken directly from the weather data and polynomial coefficients vary depending on surface roughness. (Walton, 1983, p. 71; Rowley et al, 1930)

The infrared radiation portion of the interior and exterior combined surface coefficients is based on the linearized gray-body radiation equation (Duffie and Beckman 1974):

$$
h_{i}=4 \varepsilon \sigma T^{3}, \mathrm{~W} /\left(\mathrm{m}^{2} \mathrm{~K}\right)
$$

where,

$\varepsilon=$ emissivity of surface,

$\sigma=5.67 * 10^{-8} \mathrm{~W} /\left(\mathrm{m}^{2} \mathrm{~K}^{4}\right)$ (Stefan-Boltzmann constant),

$T=$ Average temperature of surrounding surfaces, assumed $10^{\circ} \mathrm{C}(283 \mathrm{~K})$ for outside, $20^{\circ} \mathrm{C}(293 \mathrm{~K})$ for inside.

The convective portion of these coefficients was determined by subtracting out the radiative portion.

\section{Literature review on surface coefficients}

Table 1 and its accompanying notes provide comparisons of buoyancy-driven interior surface convective heat transfer coefficient calculation methods. The values labeled "J/N1995" are the original BESTEST values; the method we ultimately chose to use for the purpose of developing approximate alternative constant surface coefficients is labeled as "TARP 1983" (Walton 1983) highlighted in the table. Many of these methods, including the TARP method are model options for EnergyPlus (U.S. DOE 2018) for buoyancy-driven surface airflow. The "J/N 1995" constant values and the "C/G 1995" method are not EnergyPlus options. The TARP method is also an option in TRNSYS (Klein et al. 2018). So, "TARP 1983" is deemed appropriate for use with building energy modeling. Compared with other methods listed in Table 1, "TARP 1983" appears to have mostly better agreement with other methods than use of the "J/N1995" constant values, Specifically, for vertical surfaces, results for the TARP 1983 algorithm appear to have good agreement with correlations based on other measured data (Fohanno and Polidori 2006; Alamdari and Hammond 1983), all of which produce lower values for convective coefficients than those based on the earlier ASHRAE combined coefficients. There is some disagreement with Curcija and Goss (1995) and ISO 15099 (2003): the correlations from these sources are based on the same data sets, which applied empirical data using water rather than air as the convective transport medium. For horizontal surfaces, the correlations of TARP 1983, Alamdari and Hammond (1983), and Curcija and Goss (1995) produce lower convective coefficients than those based on the ASHRAE combined coefficients, albeit with better agreement for enhanced (unstable) convection than for retarded (stable) convection. Our preliminary simulations for this evaluation indicate that for the analyzed test cases floor convection tends to be enhanced while ceiling convection tends to be stable.

Table 1. Example Convective Surface Coefficients from a Variety of Calculation Methods

\begin{tabular}{|c|c|c|c|c|c|c|}
\hline Method & Units & h,conv & h,conv & h,conv & h,conv & h,conv \\
\hline$\Delta T$ & $\left({ }^{\circ} \mathrm{C}\right)$ & 0.5 & 1 & 5 & 10 & 15 \\
\hline Vertical & & & & & & \\
\hline J/N 1995 & $\mathrm{~W} /\left(\mathrm{m}^{2} \mathrm{~K}\right)$ & 3.16 & 3.16 & 3.16 & 3.16 & 3.16 \\
\hline A/H 1983 & $\mathrm{~W} /\left(\mathrm{m}^{2} \mathrm{~K}\right)$ & 1.15 & 1.40 & 2.26 & 2.79 & 3.17 \\
\hline F/P 2006 & $\mathrm{~W} /\left(\mathrm{m}^{2} \mathrm{~K}\right)$ & 1.09 & 1.36 & 2.25 & 2.81 & 3.19 \\
\hline TARP 1983 & $W /\left(m^{2} K\right)$ & 1.04 & 1.31 & 2.24 & 2.82 & 3.23 \\
\hline C/G 1995 & $\mathrm{~W} /\left(\mathrm{m}^{2} \mathrm{~K}\right)$ & 1.03 & 1.23 & 1.84 & 2.18 & 2.42 \\
\hline ISO 2003 & $\mathrm{~W} /\left(\mathrm{m}^{2} \mathrm{~K}\right)$ & 0.96 & 1.14 & 1.70 & 2.02 & 2.23 \\
\hline Horizontal Stab & le & & & & & \\
\hline J/N 1995 & $\mathrm{~W} /\left(\mathrm{m}^{2} \mathrm{~K}\right)$ & 1.00 & 1.00 & 1.00 & 1.00 & 1.00 \\
\hline $\mathrm{A} / \mathrm{H} 1983$ & $\mathrm{~W} /\left(\mathrm{m}^{2} \mathrm{~K}\right)$ & 0.24 & 0.28 & 0.38 & 0.44 & 0.48 \\
\hline C/G 1995 & $\mathrm{~W} /\left(\mathrm{m}^{2} \mathrm{~K}\right)$ & 0.34 & 0.40 & 0.55 & 0.63 & 0.68 \\
\hline TARP 1983 & $W /\left(m^{2} K\right)$ & 0.60 & 0.76 & 1.30 & 1.64 & 1.87 \\
\hline Horizontal Uns & table & & & & & \\
\hline J/N 1995 & $\mathrm{~W} /\left(\mathrm{m}^{2} \mathrm{~K}\right)$ & 4.13 & 4.13 & 4.13 & 4.13 & 4.13 \\
\hline A/H 1983 & $\mathrm{~W} /\left(\mathrm{m}^{2} \mathrm{~K}\right)$ & 1.15 & 1.40 & 2.26 & 2.79 & 3.17 \\
\hline C/G 1995 & $\mathrm{~W} /\left(\mathrm{m}^{2} \mathrm{~K}\right)$ & 1.26 & 1.59 & 2.72 & 3.43 & 3.92 \\
\hline TARP 1983 & $W /\left(m^{2} K\right)$ & 1.20 & 1.51 & 2.58 & 3.25 & 3.72 \\
\hline
\end{tabular}

Notes for Table 1:

J/N 1995. Judkoff and Neymark (1995). Based on ASHRAE (1981, Table 1, p. 23.12) combined coefficients with radiative portion subtracted out. These are the "original BESTEST" values provided 
(in Standard 140-2017) for programs that do not automatically calculate surface heat transfer.

A/H 1983. Alamdari and Hammond (1983). Correlations based on 9 data sets ( 8 for air, 1 for water) collected by various authors from 1922 1982, applying building-scale and smaller surfaces. Vertical surface calculation here applies height $=2 \mathrm{~m}$ (the window height); horizontal surface calculation applies hydraulic diameter $=4 \mathrm{x}$ (floor area) / (floor perimeter length) $=6.86 \mathrm{~m}$ for $8 \mathrm{~m} \times 6 \mathrm{~m}$ zone floor dimensions.

F/P 2006. Fohanno and Polidori (2006). Results are within $\leq 10 \%$ of three relatively recent, full scale, measured data sets, all for air collected by various authors from 1987 - 1999. Calculation here applies mixed laminar and turbulent convection, and a height of $2 \mathrm{~m}$ (the window height),

TARP 1983. Walton (1983), for large surfaces, citing ASHRAE (1981, p. 2.12, Table 5). Per Curcija and Goss (1995) this is based on McAdams (1954) for data taken with relatively high film temperatures (about $100^{\circ} \mathrm{C}$ ).

C/G 1995. Curcija and Goss (1995). Cites data published in 1972 using electrically heated flat plates immersed in water; this is one of the data sets cited by Alamdari and Hammond (1983). This data was also applied for developing ISO 15099 (2003), however, C/G 1995 applies more simplified formulae than ISO 2003. Per Neymark et al (1989) there can be transport fluid behavior [e.g. f(Prandtl Number)] issues when trying to emulate air behavior in water (e.g., on order of $25 \%$ lower Nusselt number in water than air for natural convection through apertures within an enclosure). Booten et al (2012) indicates C/G 1995 has better agreement with ISO 2003 than shown here; air density at altitude may be the reason as agreement improves for sea level density $=1.2 \mathrm{~kg} / \mathrm{m} 3$, while density $=1.04 \mathrm{~kg} / \mathrm{m} 3$ is applied here. (Density $=1.04 \mathrm{~kg} / \mathrm{m} 3$ is calculated from Patm at altitude, applying rough average of Patm values coincident with occurrence of $23.3^{\circ} \mathrm{C}$ dry-bulb temperature in the weather data). For vertical surface calculation here a height of $2 \mathrm{~m}$ (the window height) is applied, and for stable horizontal surfaces a characteristic length of $8 \mathrm{~m}$ (floor length) is applied; unstable horizontal convection is independent of length in this calculation.

ISO 2003. ISO 15099 (2003). Discussed in note "C/G 1995" just above The calculation here applies the following assumptions: vertical surface height $=2 \mathrm{~m}$ (the window height), environment temperature $=23.5^{\circ} \mathrm{C}$ (average of zone temperature setpoints used for developing thermal properties), air density $=1.04 \mathrm{~kg} / \mathrm{m} 3$ (see note "C/G 1995").

The exterior surface convective heat transfer calculation applies an algorithm combining wind and buoyancy driven convection. The algorithm is based on measured data for glass surfaces from Lawrence Berkeley National Laboratory's Mobile Window Thermal Test (MoWiTT) facility (Yazdanian and Klems 1994). This algorithm was selected over the original BESTEST algorithm for combined convective and radiative coefficients described above, because the MoWiTT coefficients were developed from measurements on building-scale sized surfaces applying measurement methods that have advanced since 1930. The recorded uncertainty of the MoWiTT measurements is about $\pm 2.5 \%$ for windward and $\pm 5 \%$ for leeward data at weather tower wind speed of $3 \mathrm{~m} / \mathrm{s}$.

\section{Selected correlations to derive constant surface coefficients}

The following discussion summarizes methods for calculating alternative constant interior and exterior convective surface heat transfer that were applied in detailed simulations with EnergyPlus 8.3 and TRNSYS 17.2.5 (U.S. DOE, 2015; Klein et al., 2015). These are the methods we applied for these test cases. Other methods for calculating convective portions of combined coefficients are possible; see above literature review and also Peeters \& Beausoleil-Morrison (2011) and U.S. DOE (2018).
Interior Surface Convective Coefficients (honv,int).

The interior convective heat transfer calculation applies an algorithm, see Equation 2, for buoyancy driven convection as a function of surface-to-zone-air temperature difference and surface orientation (Walton 1983). Surface roughness is not considered in this algorithm.

$$
h_{\text {conv, int }}=a\left|\Delta T_{\text {int }}\right|^{1 / 3}, \mathrm{~W} /\left(\mathrm{m}^{2} \mathrm{~K}\right)
$$

where: $a=1.31$ (vertical), 0.76 (stable horizontal), 1.52 (unstable horizontal); and where "vertical" and "horizontal" refer to surface orientation, "stable" refers to retarded convection for rising warmer air or falling cooler air driven towards a surface, and "unstable" refers to enhanced convection for rising warmer air or falling cooler air moving away from a surface; and where $\Delta \mathrm{T}_{\text {int }}$ is the temperature difference between the interior surface and zone air. The algorithm is based on measured data (ASHRAE 1981, p. 2.12, Table 5 [also see ASHRAE 2001 , p. 3.12, Table 5, although the horizontal stable " $a$ " coefficient is lower (0.59)]).

\section{Exterior surface convective coefficients $\left(\boldsymbol{h}_{\text {conv,ext }}\right)$.}

For application here, the original MoWiTT algorithm is modified for local-height wind speed (Booten et al. 2012). The modified algorithm also accounts for surface orientation (Walton 1983; ASHRAE 1981, 2001) and surface roughness (Walton 1983; Rowley et al 1930), as applied in the EnergyPlus "DOE-2 Model" (U.S. DOE 2018). The resulting model is formulated as:

$$
h_{\text {conv }, \text { ext }}=h_{n}+R_{f}\left(h_{c, \text { glass }}-h_{n}\right), \mathrm{W} /\left(\mathrm{m}^{2} \mathrm{~K}\right)
$$

where:

$h_{n}=a\left|\Delta T_{\text {ext }}\right|^{1 / 3}, \mathrm{~W} /\left(\mathrm{m}^{2} \mathrm{~K}\right)$

where the "a" coefficient is the same as in Equation 2, and where $\Delta T_{\text {ext }}$ is the temperature difference between the exterior surface and ambient dry-bulb temperature.

$R_{f}=1.67$ (Rough), 1.00 (Very Smooth); more roughness coefficients are listed elsewhere (U.S. DOE 2018; Walton 1983).

$h_{c, \text { glass }}=\left(h_{n}{ }^{2}+\left(c V_{z}{ }^{d}\right)^{2}\right)^{(1 / 2)}, \mathrm{W} /\left(\mathrm{m}^{2} \mathrm{~K}\right)$

where: $h_{n}$ is the buoyancy driven flow component described above, and $V_{z}$ is the local wind speed calculated at the height above ground of the surface centroid (see below);

and where coefficients $c$ and $d$ vary with wind direction relative to the surface as windward: $c=3.260, d=$ 0.890; leeward: $c=3.550, d=0.617$ (Booten et al. 2012; U.S. DOE 2018). Regarding definition of leeward: Yazdanian and Klems (1994, p.4) indicate their data tabulations correspond to "windward and leeward hemispheres", interpretable as leeward being definable as $>90$ degrees from normal wind incidence. The roof is always windward, consistent with EnergyPlus documentation of its "adaptive convection algorithm" options for roof exterior surface heat transfer coefficient models. (U.S. DOE 2018, p. 47)

The verified simulation calculations also apply wind speed from hourly weather data modified for the height of the respective surface centroids as indicated in the 
updated BESTEST specification (Neymark and Judkoff, et al. 2018).

\section{Methodology: calculation of alternative constant surface coefficients from verified independent simulations}

First, reference solutions were calculated independently using TRNSYS and EnergyPlus, applying automated detailed convection calculations for each time step (Equation 2 for interior surface convective heat transfer, and Equations 3 through 6 for exterior surface convective heat transfer) along with automated detailed interior surface-to-surface and exterior surface-to-outdoorsurrounding-environment radiative exchange modeling. This reference case is named " $h o$ " in the Results section.

Equivalent constant coefficients were then calculated from these reference results using the concept of loadweighted average coefficients. Load-weighted averaging was applied to give greater weight to hourly surface coefficient values when heating or cooling loads are present, i.e., when overall thermal drivers are strongest.

\section{Load-weighted-average convection coefficients}

The equivalent constant interior convection coefficient is defined as:

$$
h_{\text {conv }, \text { int }, \text { lwa }}=\frac{\sum\left(\left|h_{\text {conv, int }}\right| \cdot\left|Q_{\text {zone }}\right|\right)}{\sum\left|Q_{\text {zone }}\right|}
$$

where

$h_{\text {conv,int,lwa }}$ is the load-weighted average interior convection coefficient for a given surface.

$h_{\text {conv,int }}$ is the (hourly) interior convection coefficient reported by the simulation tool for that surface.

$Q_{\text {zone }}$ is the (hourly) calculated heating or cooling loadhere heating is defined as positive and cooling as negative, but absolute values are summed.

Sums are taken over the entire year, i.e. 8760 hourly steps. The denominator is equivalent to the sum of the absolute values of the annual heating and cooling loads.

A similar definition is used for the exterior load -weighted average convection coefficient, $h_{\text {conv, ext,lwa }}$.

\section{Load-weighted combined coefficients}

The equivalent constant interior combined coefficient is defined using the load-weighted average combined heat flux from each surface $Q_{c o m b, i n t, l w a}$ :

$$
Q_{\text {comb }, \text { int }, \text { lwa }}=\frac{\sum\left(\left|Q_{\text {conv }, \text { int }}+Q_{\text {ir,int }}\right| \cdot\left|Q_{\text {zone }}\right|\right)}{\sum\left|Q_{\text {zone }}\right|}
$$

where

$Q_{\text {convint }}$ is the (hourly) convective heat flux from the given surface to the interior air

$Q_{i r, \text { int }}$ is the (hourly) longwave (infrared) heat flux from the given surface to the interior surroundings.

It should be noted that the convective and radiative heat fluxes from the surface can have opposite signs (be in opposite directions) at a given time step. The equation above will sum the two heat fluxes with their signs, and then take the absolute value to perform the annual sum.
An equivalent load-weighted average temperature difference $\left(\Delta T_{\text {int,lwa }}\right)$ is then defined:

$$
\Delta T_{\text {int }, l w a}=\frac{\sum\left(\left|\Delta T_{\text {int }}\right| \cdot\left|Q_{\text {zone }}\right|\right)}{\sum\left|Q_{\text {zone }}\right|}
$$

where

$\Delta T_{\text {int }}$ is the (hourly) temperature difference of given interior surface and zone air dry-bulb temperature.

The equivalent combined load-weighted interior surface coefficient $\left(h_{c o m b, \text { int,lwa }}\right)$ is then given by:

$$
h_{\text {comb }, \text { int }, l w a}=\frac{Q_{\text {comb }, \text { int }, \text { lwa }}}{\Delta T_{\text {int }, l w a}}
$$

A similar definition is used to define $h_{c o m b, e x t, l w a}$, the equivalent load-weighted average combined exterior surface coefficient.

\section{Alternative Constant Coefficient Verification}

Surface coefficients calculated by the EnergyPlus and TRNSYS simulations using the above methodology have the following differences:

$h_{\text {conv,int,lwa }}: \leq 1.1 \%$, except $12 \%$ for floor $\left(0.1 \mathrm{~W} /\left(\mathrm{m}^{2} \mathrm{~K}\right)\right.$ out of $0.9 \mathrm{~W} /\left(\mathrm{m}^{2} \mathrm{~K}\right)$

$h_{\text {comb,int, } l w a}: \leq 8 \%$, mostly $<5 \%$

$h_{\text {conv, ext }, \text { lwa }}: \leq 2 \%$, except floor $=40 \%$ to $50 \%$ ( 0.3 to 0.4 $\mathrm{W} /\left(\mathrm{m}^{2} \mathrm{~K}\right)$ out of $0.8 \mathrm{~W} /\left(\mathrm{m}^{2} \mathrm{~K}\right)$

$h_{\text {comb,ext,lwa }}: \leq 13 \%$ and mostly $\leq 6 \%$, except $22 \%$ for windows stemming from different window models in the programs, and 29\% for the Case 200 floor.

Larger differences to floor $h$,conv occur because of lower limit of $1.0 \mathrm{~W} /\left(\mathrm{m}^{2} \mathrm{~K}\right)$ in TRNSYS. The effect of larger differences for the floor exterior coefficients is negligible because the BESTEST floor is highly insulated. Differences for $h$, comb are greater than for $h$,conv because of radiation modeling differences.

We consider this to be reasonable agreement, such that the evaluated coefficients are verified in the context of the BESTEST specification, and we can apply the average value of the two simulations for each surface to obtain the alternative constant coefficient values described below.

\section{Results}

Updated versus prior alternative constant convective and combined (convective and radiative) surface heat transfer coefficients are shown in Table 2. These are average values from the EnergyPlus and TRNSYS simulations that apply the calculation methodology described above. This table provides coefficients for interior and exterior surfaces, disaggregated for surfaces with $\varepsilon=0.9$ and $\varepsilon=$ 0.1 , where $\varepsilon$ is surface infrared emittance. The following BESTEST cases were applied for developing the simplified constant coefficients: Case 600, low mass base case with $\varepsilon=0.9$; Case 200, $\varepsilon=0.1$ and high-conductance wall elements in place of windows. Values for highconductance wall elements with $\varepsilon=0.9$, where they occur in some of the BESTEST cases, are the same as for the transparent windows.

The following nomenclature applies in Table 2: 
- h,conv,int: interior convective surface coefficient

- h,conv,ext: exterior convective surface coefficient

- h,comb,int: interior combined surface coefficient

- h,comb, ext: exterior combined surface coefficient

- "New" indicates values of the constant annual zone load-weighted average convective and combined coefficients evaluated for the process described above.

- "1995" indicates values from Standard 140-2017 (ANSI/ASHRAE 2017), originally published in IEA BESTEST (Judkoff and Neymark 1995); these values have been applied in Standard 140 since its first version (ANSI/ASHRAE 2001).

- "n/a": not applicable, only for the " 1995 " floor exterior surface coefficients.

- "8.0 or 8.3" in the cell for column labeled "Window or High Cond. Wall Elements", "1995”, and row for " $\varepsilon=0.9$, interior", "h,comb,int": indicates values of $8.0 \mathrm{~W} /\left(\mathrm{m}^{2} \mathrm{~K}\right)$ and $8.3 \mathrm{~W} /\left(\mathrm{m}^{2} \mathrm{~K}\right)$ for the window $(\varepsilon=$ $0.84)$ and high-conductance wall elements $(\varepsilon=0.9)$, respectively.

For the "New" coefficients, which stem from more detailed evaluation than the " 1995 " coefficients, $h_{\text {comb }}<$ $h_{\text {conv }}$ is possible because convective and radiative heat flows may be in opposite directions for a given surface for a sufficient number of time steps; this is not accounted for in the "1995" coefficients.

Table 2. Comparison of Forthcoming New Versus Original-Standard-140 Alternative Constant Surface Heat Transfer Coefficients ${ }^{1,2}$

\begin{tabular}{|c|c|c|c|c|c|c|c|c|}
\hline Surface Type & \multirow{2}{*}{\multicolumn{2}{|c|}{$\begin{array}{l}\text { Windows or } \\
\text { High-Cond. } \\
\text { Wall } \\
\text { Elements }\end{array}$}} & \multirow{2}{*}{\multicolumn{2}{|c|}{ Walls }} & \multirow{2}{*}{\multicolumn{2}{|c|}{ Ceiling }} & \multirow{2}{*}{\multicolumn{2}{|c|}{ Floor }} \\
\hline \multirow{2}{*}{$\begin{array}{l}\text { Surface Coeff., } \\
W /\left(\mathrm{m}^{2} \cdot \mathrm{K}\right) \\
\varepsilon=0.9, \text { Interior }\end{array}$} & & & & & & & & \\
\hline & New & 1995 & New & 1995 & New & 1995 & New & 1995 \\
\hline h,conv,int, & 2.4 & 3.2 & 2.2 & 3.2 & 1.8 & 3.2 & 2.2 & 3.2 \\
\hline h,comb,int & 4.5 & $\begin{array}{r}8.0 \\
\text { or } 8.3 \\
\end{array}$ & 1.8 & 8.3 & 1.7 & 8.3 & 3.7 & 8.3 \\
\hline \multicolumn{9}{|l|}{$\varepsilon=0.9$, Exterior } \\
\hline h,conv,ext & 8.0 & 16.4 & 11.9 & 24.7 & 14.4 & 24.7 & 0.8 & $n / a$ \\
\hline h,comb,ext & 17.8 & 21.0 & 21.6 & 29.3 & 21.8 & 29.3 & 5.2 & $n / a$ \\
\hline \multicolumn{9}{|l|}{$\varepsilon=0.1$, Interior } \\
\hline $\mathrm{h}$,conv,int & 2.6 & 3.2 & 1.9 & 3.2 & 1.9 & 3.2 & 1.0 & 3.2 \\
\hline $\mathrm{h}$,comb,int & 3.1 & 3.7 & 2.1 & 3.7 & 1.9 & 3.7 & 0.4 & 3.7 \\
\hline \multicolumn{9}{|l|}{$\varepsilon=0.1$, Exterior } \\
\hline $\mathrm{h}$, conv,ext & 7.9 & 16.4 & 11.8 & 24.7 & 14.4 & 24.7 & 0.9 & $\mathrm{n} / \mathrm{a}$ \\
\hline h,comb,ext & 8.1 & 16.9 & 12.8 & 25.2 & 17.4 & 25.2 & 1.3 & $n / a$ \\
\hline
\end{tabular}

1. Example constant surface coefficients presented here apply only to the test cases, and only for test cases with south facing windows or south facing high-conductance wall elements. They should not be assumed to apply beyond the updated BESTEST suite.

2. Example constant interior surface coefficients assume buoyancy regime heat transfer only.

Table 3 provides a comparison of annual heating and cooling load results applying the "New" and "1995" coefficients versus results for automated hourly calculations applying the algorithms described above for Case $600(\varepsilon=0.9)$ and Case $200(\varepsilon=0.1)$. The run designations for the case inputs in the column headers of Table 3 are defined as follows:

- ho: Base case (benchmark for comparison of other constant coefficient runs described below) run with:

- Automated detailed convection calculations applying Equation 2 for interior surface convective heat transfer, and Equations 3 through 6 for exterior surface convective heat transfer, for each time step

- Automated detailed interior surface-to-surface and exterior surface-to-outdoor-surroundingenvironment radiative exchange modeling.

- hli:

- Constant interior convective coefficients (h,conv,int,lwa)

- Automated interior surface-to-surface radiative exchange

- Automated exterior surface convection and radiation exchange.

- hle:

- Constant exterior convective coefficients (h,conv,ext,lwa)

- Automated exterior surface-to-outdoorsurrounding-environment radiative exchange

- Automated interior surface convection and radiation exchange.

- hlie:

- Constant interior and exterior convective coefficients (h,conv,int,lwa and h,conv,ext,lwa)

- Automated interior surface-to-surface and exterior surface-to-outdoor-surrounding-environment radiative exchange.

- $h 2 i$ :

- Constant interior combined coefficients (h,comb,int,lwa)

- Automated interior surface convection and radiative exchange modeling disabled or minimized (e.g., set interior surface $\varepsilon=0.0000001$ )

- Automated exterior surface convection and radiation exchange.

- $h 2 e$ :

- Constant exterior combined coefficients (h,comb,ext,lwa)

- Automated exterior surface convection and radiative exchange modeling disabled or minimized (e.g., set exterior surface $\varepsilon=0.000001$ )

- Automated interior surface convection and radiation exchange.

- h2ie:

- Constant interior and exterior combined coefficients (h,comb,int,lwa and h,comb,ext,lwa)

- Automated interior and exterior surface convection and radiative exchange modeling disabled or minimized (e.g., set all surface $\varepsilon=0.0000001$ ).

- "95" suffix to above (h1i95, hle95, hlie95, h2i95, h2e95, h2ie95): This indicates the same scheme as above, except "1995" alternative constant coefficients are applied where appropriate in place of the "New" alternative constant coefficients (see Table 2). 
Table 3. Loads for Automated (h0) Runs and \% Differences Versus h0 Runs Applying "New" and "1995" Coefficients

Loads for Automated (h0) Runs and \% Differences Versus ho Runs Applying 2016 (New) and Original (1995) Coefficients

\begin{tabular}{|c|c|c|c|c|c|c|c|c|c|c|c|c|c|}
\hline Case & $\begin{array}{c}\text { ho } \\
\text { MWh/y }\end{array}$ & $\begin{array}{c}\text { h1i v h0 } \\
\% \text { diff }\end{array}$ & $\begin{array}{l}\text { h1e v h0 } \\
\% \text { diff }\end{array}$ & $\begin{array}{c}\text { h1ie v ho } \\
\% \text { diff }\end{array}$ & $\begin{array}{c}\text { h2i v h0 } \\
\text { \% diff }\end{array}$ & $\begin{array}{c}\text { h2e v h0 } \\
\text { \% diff }\end{array}$ & $\begin{array}{c}\text { h2ie v h0 } \\
\% \text { diff }\end{array}$ & $\begin{array}{c}\text { h1i95 v h0 } \\
\% \text { diff }\end{array}$ & $\begin{array}{c}\text { h1e95 v h0 } \\
\% \text { diff }\end{array}$ & $\begin{array}{c}\text { h1ie95 v h0 } \\
\% \text { diff }\end{array}$ & $\begin{array}{c}\text { h2i95 v h0 } \\
\% \text { diff }\end{array}$ & $\begin{array}{c}\text { h2e95 v h0 } \\
\% \text { diff }\end{array}$ & $\begin{array}{c}\text { h2ie95 v h0 } \\
\% \text { diff }\end{array}$ \\
\hline \multicolumn{14}{|c|}{ TRNSYS Annual Heating } \\
\hline 600 & 4.475 & $0.6 \%$ & $0.0 \%$ & $0.6 \%$ & $-4.3 \%$ & $-8.1 \%$ & $-12.4 \%$ & $11.0 \%$ & $1.1 \%$ & $12.1 \%$ & $24.0 \%$ & $-6.8 \%$ & $15.6 \%$ \\
\hline 200 & 5.151 & $-0.6 \%$ & $1.5 \%$ & $0.7 \%$ & $1.3 \%$ & $-0.8 \%$ & $0.5 \%$ & $8.9 \%$ & $8.7 \%$ & $18.1 \%$ & $10.6 \%$ & $7.1 \%$ & $18.3 \%$ \\
\hline \multicolumn{14}{|c|}{ TRNSYS Annual Cooling } \\
\hline 600 & 5.712 & $-1.5 \%$ & $-0.9 \%$ & $-2.3 \%$ & $8.2 \%$ & $3.8 \%$ & $12.4 \%$ & $9.3 \%$ & $-9.1 \%$ & $-0.2 \%$ & $25.8 \%$ & $-1.2 \%$ & $24.2 \%$ \\
\hline 200 & 0.789 & $7.5 \%$ & $-2.8 \%$ & $4.6 \%$ & $11.0 \%$ & $2.2 \%$ & $13.1 \%$ & $21.3 \%$ & $-11.0 \%$ & $9.1 \%$ & $23.8 \%$ & $-7.4 \%$ & $15.5 \%$ \\
\hline \multicolumn{14}{|c|}{ TRNSYS Annual Heating + Cooling } \\
\hline 600 & 10.187 & $-0.6 \%$ & $-0.5 \%$ & $-1.1 \%$ & $2.7 \%$ & $-1.4 \%$ & $1.5 \%$ & $10.1 \%$ & $-4.6 \%$ & $5.2 \%$ & $25.0 \%$ & $-3.7 \%$ & $20.4 \%$ \\
\hline 200 & 5.940 & $0.5 \%$ & $0.9 \%$ & $1.2 \%$ & $2.6 \%$ & $-0.4 \%$ & $2.1 \%$ & $10.5 \%$ & $6.1 \%$ & $16.9 \%$ & $12.4 \%$ & $5.2 \%$ & $17.9 \%$ \\
\hline \multicolumn{14}{|c|}{ EnergyPlus Annual Heating } \\
\hline 600 & 4.423 & $0.2 \%$ & $0.3 \%$ & $0.4 \%$ & $-6.3 \%$ & $-5.9 \%$ & $-12.1 \%$ & $9.4 \%$ & $2.8 \%$ & $12.4 \%$ & $17.0 \%$ & $-2.8 \%$ & $14.0 \%$ \\
\hline 200 & 5.085 & $-0.4 \%$ & $1.7 \%$ & $1.2 \%$ & $1.5 \%$ & $-0.6 \%$ & $0.7 \%$ & & & & & & \\
\hline \multicolumn{14}{|c|}{ EnergyPlus Annual Cooling } \\
\hline 600 & $6.067 \mid$ & $-2.4 \%$ & $-1.3 \%$ & $-3.6 \%$ & $7.2 \%$ & $1.4 \%$ & $8.8 \%$ & $7.3 \%$ & $-10.7 \%$ & $-3.8 \%$ & $19.1 \%$ & $-5.9 \%$ & $12.7 \%$ \\
\hline 200 & 0.818 & $7.7 \%$ & $-3.3 \%$ & $4.4 \%$ & $11.0 \%$ & $0.9 \%$ & $11.7 \%$ & & & & & & \\
\hline \multicolumn{14}{|c|}{ EnergyPlus Annual Heating + Cooling } \\
\hline 600 & | 10.490 & $-1.3 \%$ & $-0.6 \%$ & $-1.9 \%$ & $1.5 \%$ & $-1.7 \%$ & $0.0 \%$ & $8.2 \%$ & $-5.0 \%$ & $3.1 \%$ & $18.2 \%$ & $-4.6 \%$ & $13.3 \%$ \\
\hline
\end{tabular}

Results for constant coefficient runs were produced using the individual constant surface coefficients from each program (not shown in Table 2 because of space limitations), so there were minor input differences. Load results in Table 3 indicate the following:

- All \%-differences between EnergyPlus and TRNSYS results are $<7 \%$ (not explicitly shown in Table 3 because of space limitations), with most differences substantially less than that; these are attributable to differences among the overall programs and models applied by the users. This is good agreement, further verifying the derived alternative constant coefficients within the approximate range of difference, given the algorithms applied (see Equations 2 through 6).

- The "New" constant interior and exterior convective coefficients have better agreement versus the automated surface heat transfer calculations than the "1995" coefficients.

- The "New" constant interior combined coefficients have better agreement versus automated surface heat transfer calculations than the "1995" coefficients.

- For the summed annual heating + cooling loads the "New" constant exterior combined coefficients also have better agreement versus automated hourly heat transfer calculations than the "1995" coefficients. However, and while the variations are small, for some disaggregated annual heating and cooling loads the "1995" coefficients have better agreement versus automated surface heat transfer calculations than the "New" coefficients. This is possible because the constant surface coefficient development scheme minimizes error on the total combined heating and cooling loads occurring during an annual simulation.

Differences between peak hourly heating and cooling loads (not shown above) are generally similar to differences in annual loads, with slightly larger variations.

Improvement to BESTEST Example Results Agreement Figure 1 compares ranges of disagreement for the 1995 BESTEST (blue lines; individual 1995 results are black and white patterned bars) versus range of results-inprogress for the updated test spec (red bars). The red bars summarize the range (minima and maxima) for 8 sets of simulation results, including EnergyPlus, TRNSYS, and six other programs applying a variety of modeling methods. Here, annual heating loads are shown for both the low-mass and high-mass base cases (Cases 600 and 900 , respectively). The major improvement to the base cases of the new BESTEST specification is for surface heat transfer input equivalence. There were a number of other improvements of less substantial impact, including minor updates of: window construction properties, superinsulated floor, site altitude and terrain details, infiltration airflow rate for site altitude, etc. (Neymark and Judkoff, et al. 2018). Also, although the TMY3 weather data for the new test cases are for similar location (Denver, Colorado) as the TMY data for 1995, there are some differences: E.g., annual average temperature and global horizontal solar radiation are $9.7^{\circ} \mathrm{C}$ (TMY) versus $10.9^{\circ} \mathrm{C}$ (TMY3) and $1832 \mathrm{kWh} / \mathrm{m}^{2}$ (TMY) versus $1670 \mathrm{kWh} / \mathrm{m}^{2}$ (TMY3), respectively.

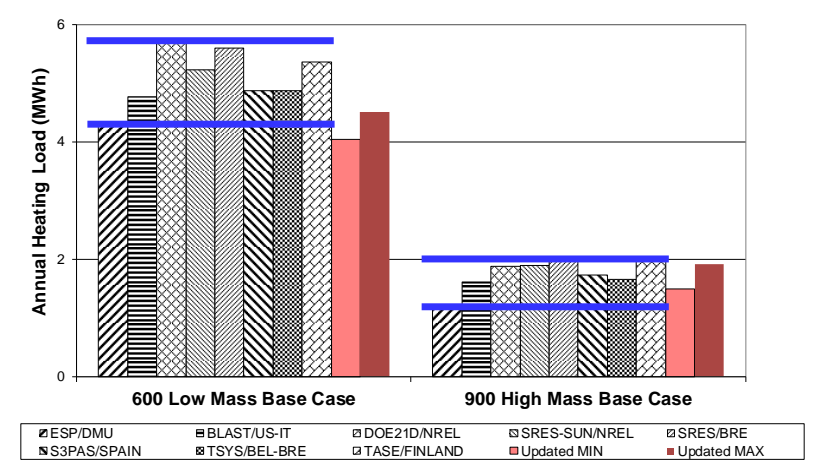

Figure 1: BESTEST Base Case Annual Heating Loads, Improvement to Ranges of Disagreement: New Results (Red Bars) Versus 1995 Results (Black Pattern Bars)

The range of disagreement is assessed by (Max Min $) /((\operatorname{Max}+\operatorname{Min}) / 2)$ expressed in \%. For the new results there is a decrease in range of disagreement of annual 
heating loads from $28 \%$ to $11 \%$ for Case 600 and from $54 \%$ to $25 \%$ for Case 900 . The Case 900 improvement may not be as easy to see in this figure because of scaling. Other test specification clarifications since 1995, noted above, may also be contributing to this improvement.

\section{Discussion and conclusions}

Update of the building thermal fabric test cases that comprise Section 5.2 of Standard 140, and related example simulation results, is nearing completion; the work described here is a key component of this update.

\section{Primary Innovation}

An important aspect of the BESTEST methodology is to provide test specifications with equivalent inputs that satisfy a variety of simulation program input schemes, thereby reducing disagreement among program results attributable to interpretive input issues. The primary scientific innovation of this work is to improve diagnostic capability by providing improved BESTEST/Standard 140 equivalent inputs for surface heat transfer models that accommodate improvements to the state of the art in surface heat transfer modeling. This mitigates "background noise" of variation of surface heat transfer models that is present in the original example simulation results published in 1995. Addressing this known source of disagreement contributes to narrowing the range of disagreement among example results, thereby enhancing the diagnostic power of the procedure to find other sources of disagreement in the internal math and physics of BEM programs.

In addition to the simulation work described here, we have included a survey and comparison of a number of recently developed convective heat transfer algorithms for the buoyancy flow regime.

\section{Major Accomplishments}

- EnergyPlus and TRNSYS simulations were performed by two independent modelers to: 1) compare the automated calculations of the models when applying similar convective heat transfer algorithms for the buoyancy-driven flow regime and their default radiation exchange algorithms, 2) develop updated equivalent alternative constant surface coefficients consistent with the above automated calculations, and 3 ) assess effects of revised constant coefficients on simulated loads. Comparison of new constant coefficients versus BESTEST coefficients published in 1995 is summarized in previous sections.

- Preliminary results indicate substantially improved agreement between simulations applying new constant coefficients versus the 1995 coefficients when compared with the automated simulations. This contributes to improved agreement among newly tested programs for the BESTEST suite update-inprogress: e.g., range of annual heating loads for the low mass and high mass base cases, respectively, are improving from $28 \%$ in 1995 to $11 \%$ and from $54 \%$ in 1995 to $25 \%$. However, even with this improvement there are limits to the ability of constant coefficients to model surface heat transfer physics. This is particularly true for combined radiative and convective coefficients, because radiative heat flux and convective heat flux for a given surface are observed in the EnergyPlus and TRNSYS models to be in the same or opposite directions as a function of time during an annual simulation.

\section{Acknowledgements}

Jason Glazer, Robert Henninger, and Michael Witte of GARD Analytics, Inc., Arlington Heights, IL, provided EnergyPlus input files to Mr. Neymark for use with his further analysis. Mike Witte also provided review of this material in the forthcoming project final report.

Marion Hiller of TRANSSOLAR Energietechnik GmbH, Germany, worked with Dr. Kummert on verification of his TRNSYS input files and results.

We appreciate the support and guidance of Amir Roth, U.S. Department of Energy (DOE) program manager.

We are also grateful for the ASHRAE organizational framework that facilitated this project.

This paper was developed based upon funding from the Alliance for Sustainable Energy, LLC, Managing and Operating Contractor for the National Renewable Energy Laboratory for the U.S. Department of Energy.

\section{Nomenclature}

ANSI American National Standards Institute

ASHRAE American Society of Heating, Refrigerating and Air-Conditioning Engineers

BEM Building Energy Model

BESTEST Building Energy Simulation Test and Diagnostic Method

IEA International Energy Agency

IBPSA International Building Performance Simulation Association

NREL National Renewable Energy Laboratory

\section{References}

Alamdari, F. and G.P. Hammond. (1983). Improved Data Correlations for Buoyancy-Driven Convection in Rooms. Building Services Engineering Research \& Technology. Vol. 4, No. 3.

ANSI/ASHRAE. (2001, 2017). ANSI/ASHRAE Standard 140-2017. Standard Method of Test for the Evaluation of Building Energy Analysis Computer Programs. Atlanta, Georgia, U.S.A.: ASHRAE.

ANSI/ASHRAE/IES. (2016). ANSI/ASHRAE/IES Standard 90.1-2016, Energy Standard for Buildings Except Low-Rise Residential Buildings. Atlanta, Georgia, U.S.A.: ASHRAE.

ANSI/ASHRAE/IES/USGBC. (2017) ANSI/ASHRAE/ IES Standard 189.1-2017, Standard for the Design of High-Performance Green Buildings, Except Low-Rise Residential Buildings. Atlanta, GA, US: ASHRAE.

ASHRAE (1981, 2001, 2017). Handbook of Fundamentals. Atlanta, Georgia, US: ASHRAE. 
ASHRAE 2001 HoF Table 5, p. 3.12 (also ASHRAE 1981, Table 5, p. 2.12) is revised after 2001.

Bloomfield, D.; ed. 1989. Design Tool Evaluation: Benchmark Cases. IEA T8B4. Solar Heating and Cooling Programme, Task VIII: Passive and Hybrid Solar Low-Energy Buildings. Garston, Watford, UK: Building Research Establishment.

Booten, C., N. Kruis, and C. Christensen. (2012). Identifying and Resolving Issues in EnergyPlus and DOE-2 Window Heat Transfer Calculations. NREL/TP-5500-55787. Golden, Colorado: NREL.

Crawley, D.; Hand, J.; Kummert, M.; Griffith, B. (2005). "Contrasting the Capabilities of Building Energy Performance Simulation Programs." Proceedings 9th International IBPSA Conference, Montreal, Canada, August 15-18, 2005.

Curcija, D. and Goss, W.P. 1995. New Correlations for Convective Heat Transfer Coefficient on Indoor Fenestration Surfaces - Compilation of More Recent Work. ASHRAE/DOE/BTECC Conference, Thermal Performance of the Exterior Envelopes of Buildings VI, Clearwater, FL, 1995.

Duffie, J.A., and W.A. Beckman. 1974. Solar Energy Thermal Processes. New York: John Wiley \& Sons.

Fohanno, S. and G. Polidori. (2006). Modelling of Natural Convective Heat Transfer at an Internal Surface. Energy and Buildings 38 (2006) 548-553. Elsevier.

IECC. (2018). 2018 International Energy Conservation Code. Country Club Hills, IL: International Code Council.

ISO 15099. 2003. ISO 15099-2003. Thermal Performance of Windows, Doors, and Shading Devices - Detailed Calculations. International Organization for Standardization.

Judkoff, R. (1988). "Validation of Building Energy Analysis Simulation Programs at the Solar Energy Research Institute." Energy and Buildings, Vol. 10, No. 3. Lausanne, Switzerland: Elsevier Sequoia.

Judkoff, R.; Neymark, J. (1995). International Energy Agency Building Energy Simulation Test (IEA BESTEST) and Diagnostic Method. NREL/TP-4726231. Golden, Colorado, U.S.A.: NREL.

Judkoff, R.; Neymark, J. (2006). "Model Validation and Testing: The Methodological Foundation of ASHRAE Standard 140." ASHRAE Transactions, 112 (2) 367376. Atlanta, Georgia, U.S.A.: ASHRAE.

Judkoff, R.; Neymark, J. (2013). "Twenty Years On!: Updating the IEA BESTEST Building Thermal Fabric Test Cases for ASHRAE Standard 140." Proceedings of Building Simulation 2013. Chambéry, France. IBPSA. Preprint version, NREL Report CP-550058487. Golden, CO: NREL.

Klein, S.A., W.A. Beckman, J.W. Mitchell, J.A. Duffie, N.A. Duffie, T.L. Freeman, J.C. Mitchell, J.E. Braun, B.L. Evans, J.P. Kummer, R.E. Urban, A. Fiksel, J.W.
Thornton, N.J. Blair, P.M. Williams, D.E. Bradley, T.P. McDowell, M. Kummert, M.J. Duffy, et al. (2015, 2018). TRNSYS 17 - A TRaNsient SYstem Simulation program, User manual. Version 17.2.5. Madison, WI: University of Wisconsin-Madison.

McAdams, W.H. 1954. Heat Transmission. New York: McGraw-Hill.

Neymark, J., Boardman, C.R., Kirkpatrick, A., Anderson, R. 1989. High Rayleigh Number Natural Convection in Partially Divided Air and Water Filled Enclosures. International Journal of Heat and Mass Transfer, Vol. 32, No. 9, pp. 1671 - 1679, 1989. United Kingdom: Pergamon Press pic.

Neymark, J.; Kennedy, M.; Judkoff, R.; with Gall, J.; Henninger, R.; Hong, T.; Knebel, D.; McDowell, T.; Witte, M.; Yan, D.; Zhou, X. (2017). “Airside HVAC BESTEST: HVAC Air-Distribution System Model Test Cases for ASHRAE Standard 140.” Proceedings of Building Simulation 2017. San Francisco, California, United States, 7-9 Aug 2017. IBPSA.

Neymark, J.; Judkoff, R.; et al.* (2018). Update of Standard 140-2017 Section 5.2 and Related Sections (IEA BESTEST Building Thermal Fabric Test Cases), Test specification for Simulation Trial \#5. Golden, Colorado: NREL. September 2018. DRAFT. Not for External Distribution. *Full author listing to be included upon project completion.

Peeters, L., I. Beausoleil-Morrison, and A. Novoselac. (2011). "Internal Convective Heat Transfer Modeling: Critical Review and Discussion of Experimentally Derived Correlations." Energy and Buildings 43 (9): 2227-2239. doi:10.1016/j.enbuild.2011.05.002.

Rowley, F.B., A.B. Algren, and J. L. Blackshaw. (1930). "Surface Conductances as Affected by Air Velocity, Temperature and Character of Surface." ASHVE Transactions, Vol. 36, 1930. American Society of Heating and Ventilating Engineers (predecessor of ASHRAE).

U.S. DOE. (2015, 2018). EnergyPlus Engineering Reference. Washington, DC: United States Department of Energy; Urbana, IL: University of Illinois; Berkeley, CA: University of California and Lawrence Berkeley National Laboratory.

Walton, G.N. (1983). Thermal Analysis Research Program (TARP) Reference Manual. U.S. Department of Commerce, National Bureau of Standards, National Engineering Laboratory, Building Physics Division, Washington, D.C., March 1983.

Yazdanian, M., and J. Klems. (1994). "Measurement of the Exterior Convective Film Coefficient for Windows in Low-Rise Buildings." $A S H R A E$ Transactions 100(1) 1994. Atlanta, Georgia, US: American Society of Heating, Refrigerating, and AirConditioning Engineers, Inc. Also published as LBL34717. Berkeley, California. Lawrence Berkeley National Laboratory. 